\title{
Mini-review
}

\section{Trends in the use of protozoa in the assessment of wastewater treatment}

\author{
Ana Nicolau, Nicolina Dias, Manuel Mota, Nelson Lima* \\ Centro de Engenharia Biológica - IBQF, Universidade do Minho, 4710-057 Braga, Portugal \\ Received 18 January 2001; accepted 29 March 2001
}

\begin{abstract}
Increasing environmental pollution and the continuous development of new chemicals and drugs has led to ever growing concern about the potential effects of these compounds directly or indirectly on human health. As concerns water pollution, protozoa seem to be an excellent tool to assess both toxicity and pollution: they are regarded as biological indicators of pollution when their presence or absence can be related to particular environmental conditions, and they are considered test organisms when a species or population is used to evaluate the toxicity of relevant toxic compounds. Thus, an integrated approach is being developed to assess how toxic compounds affect the different biological levels of organisation - from the community level to the species level - of ciliated protozoa. The present paper reports and discusses the current state of the art of this approach. ๑ 2001 Éditions scientifiques et médicales Elsevier SAS
\end{abstract}

\section{ciliated protozoa / activated sludge / toxicity / biological indicator / test organism}

\section{Introduction}

The mechanisms by which toxicants affect organisms can be assessed in two major ways: by observing the cytological and physiological characteristics in a single population with the ultimate goal of constructing a life table (figure 1) and by studying the consequences of the toxicant in the maintenance of several populations within a community.

\section{A microbiological community of activated sludge}

In recent years, the presence of toxicants in the aquatic environment has become a common occurrence. Originating mainly from industrial sewage, they reduce the efficiency of biological wastewater treatments due to intoxication phenomena. Heavy metals are toxic to most microorganisms even at moderate concentrations, but the mechanisms by which they affect the biological systems are not well defined. Though the general response of biological wastewater treatment systems to varying concentrations of heavy metals is well documented, only in the

\footnotetext{
* Correspondence and reprints.

E-mail address: nelson@iec.uminho.pt (N. Lima).
}

last few years have investigators became aware of the influence that this class of pollutants may have upon activated sludge microfauna $[1,3,9-11,14,18-21$, 36]. Different organisms can present varying sensitivities to chemicals; moreover, the sensitivity of a single species may vary from one toxicant to another. This means that a model of action of a set of chemicals found for one species can hardly be applied to another one. However, the toxicity of a chemical or set of chemicals in terms of depletion of both organisms and species can be demonstrated by testing the whole microfauna community inhabiting the activated sludge [21].

Activated sludge treatment processes are based on formation of bacterial aggregates and other associated organisms which may be easily separated from the effluent in sedimentation tanks. Ciliated protozoa often reach densities of about $10^{7}$ cells $\mathrm{L}^{-1}$ in the aeration tank $[18,19]$ and play an essential role in the purification process by removing, through grazing, the majority of dispersed bacteria, which would cause high turbidity in the final effluent. They are very sensitive to environmental variations and, furthermore, it is recognised that changes in the protozoan community may affect the whole food web of these artificial ecosystems, thus affecting the biological performance of wastewater treatment plants; the structure of the protozoan community is 

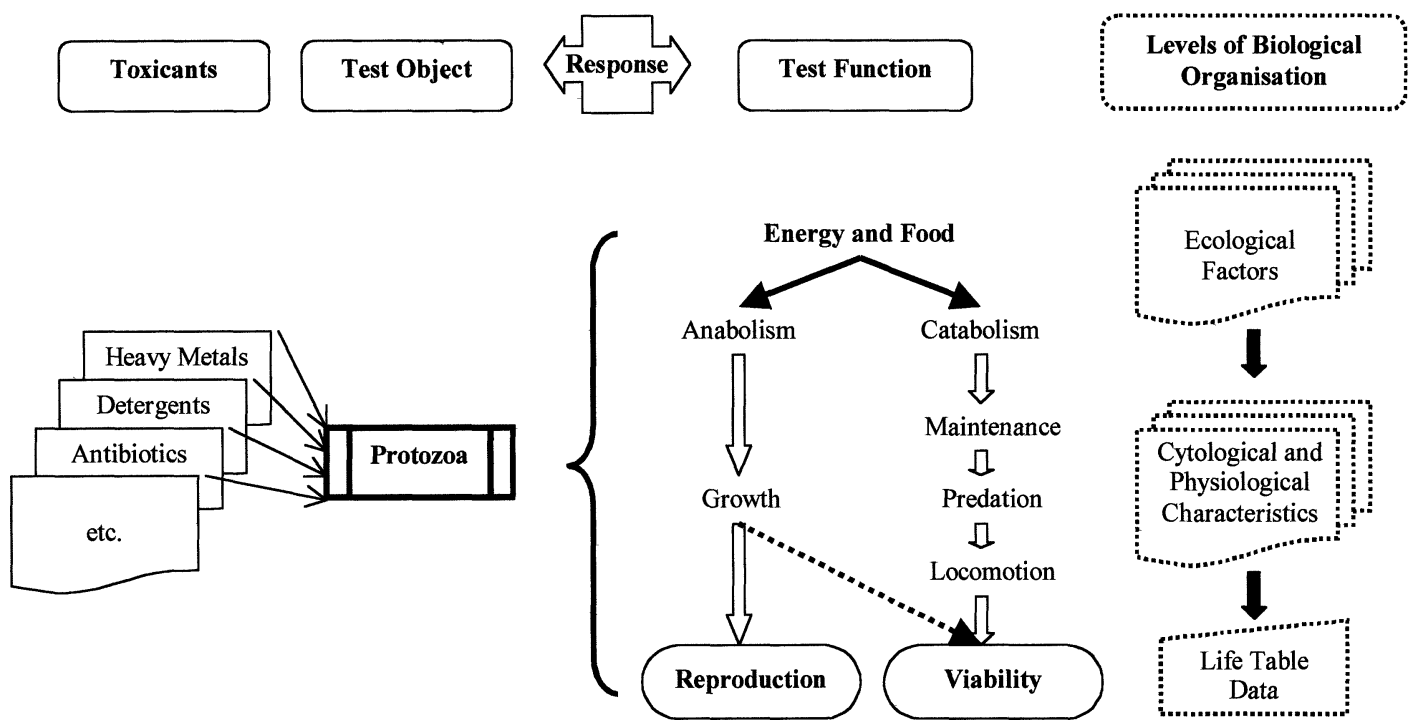

Figure 1. Conceptual framework showing the integrated approach of the parameters studied to assess the protozoan condition in wastewater treatment.

therefore an indicator of the operating conditions of the plants [5, 16, 18-21, 26, 36].

Most ciliates present in biological wastewater treatment plants feed, via filtration processes, upon dispersed populations of bacteria and can be divided into three main groups according to their feeding behaviour [19]: free swimmers, which swim in the sludge liquid fraction and remain in suspension in the sedimentation tank; attached ciliates, which are attached to the bacterial aggregates and settle in the sedimentation tank; and crawlers, which live in the floc surface and also settle in the sedimentation tank. A population of organisms associated with the flocs are at great advantage compared to those which swim freely in the liquid fraction and thus can be washed out of the system through the effluent. Furthermore, free swimming and attached ciliates are food competitors for dispersed bacteria whereas the crawling ciliates, with a "ventral mouth", feed on the lightly adherent bacteria of the floc surface [19], living in an exclusive ecological niche. In healthy established activated sludge, the latter are therefore prevalent.

In this context, Madoni [19] suggested the use of the Sludge Biotic Index (SBI) based on the abundance and diversity of the protozoan community in the activated sludge of the aeration tank and on the differing sensitivities revealed, by some of the microfauna groups to physicochemical and operational factors prevailing in the system. The SBI may range from 0 , indicating the worst condition, to 10 , indicating the most favorable condition. Numerical evaluation allows for the comparison of different sludges or of sludge biological quality through time, and is based on the relationship occurring between the structure of the microfauna and the operating conditions and performance of the studied plant.

\section{Effects of toxicants on the protozoan community}

To study the influence of toxicants on the microfauna community, two experimental wastewater plants (figure 2) were exposed to several copper concentrations in order to provide better understanding of the protozoa community evolution along with the performance of the treatment plant. A first set of assays was carried on with synthetic sewage; then the assays were repeated with real sewage, enabling the comparison of results.

This study led to similar conclusions for both experiments (submitted for publication): 1) copper affects the efficiency of the activated sludge process, but also affects the sludge microfauna and the two effects may be related, in light of current knowledge of the importance of the microfauna in activated sludge 


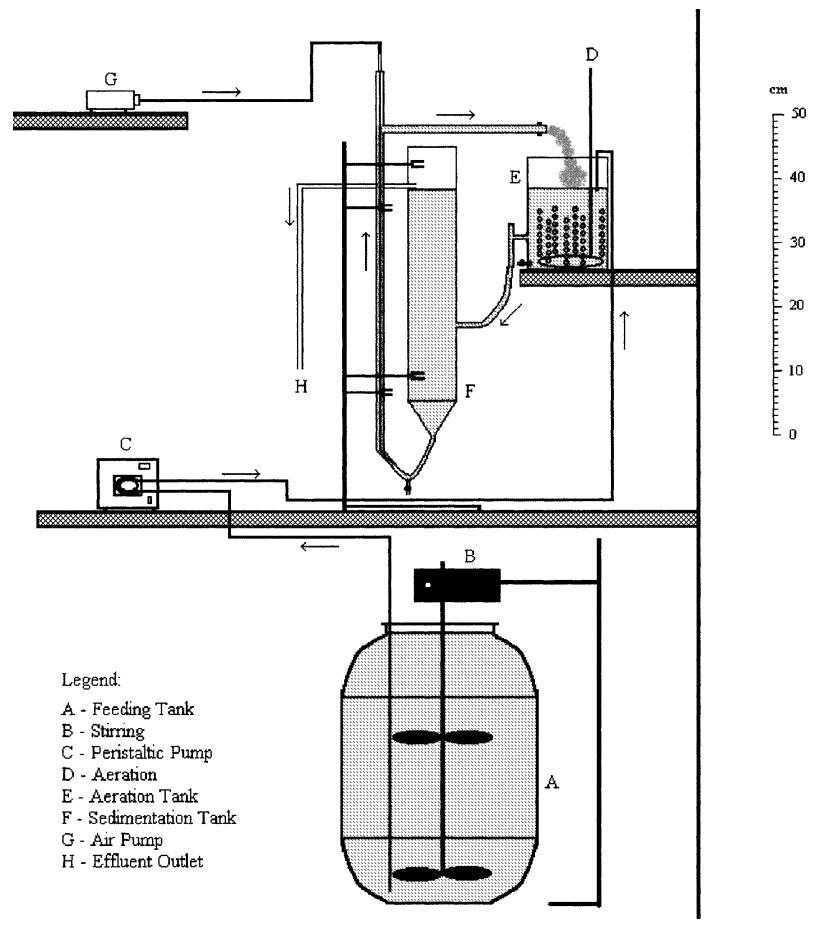

Figure 2. Experimental prototypes of wastewater treatment plants used in the study of the protozoan community following exposure to toxicants. Scale bar on the right.

processes; the structure of microfauna was affected by changing both species dominance and density; 2) high concentrations of copper strongly affected the microfauna community, but recovery occurred without any special measures, in the range of concentrations tested. Sludge efficiency in removing dissolved organic matter was also affected, but recovered even sooner than the microfauna. This corroborates the idea that both sludge bacteria and protozoa are able to survive in the presence of heavy metals, namely copper, and this highlights the possibility that purification can proceed even when additional amounts of copper are entering the system: however, heavy metals are likely to bioaccumulate - in sludge, in this particular case - and sludge is often used in the amendment of agricultural soils; 3 ) low concentrations of copper seem to have a stimulatory effect, not only on the removal efficiency of COD (chemical oxygen demand), but also on the growth of some species, namely the crawling forms. Acineria uncinata and Aspidisca cicada, in our study, showed a remarkable tolerance to low concentrations of copper in the assays with synthetic and real sewage, respectively. Other authors have mentioned the occurrence of A. cicada in these situations [1, 21, 36]. Crawling forms are in general considered useful indicators of good quality of water treatment $[18,19]$, but these results indicate that the concept must not be generalised whenever there is a risk of contamination by heavy metals. On the other hand, Opercularia sp. seems to be exceptionally tolerant to copper, emphasising the well documented resistance of these species to stressful environmental conditions; they are particularly frequent in plants receiving industrial waste containing toxic substances [14] and show a close association with poor quality of the activated sludge [19]; 4) results were comparable in the two experiments, i.e. with synthetic and real sewage, despite the problems due to the uncontrolled variability of real sewage and the gradual supremacy of carnivores occurring when synthetic sewage was supplied; 5) the sludge biotic index (SBI) closely reflected the efficiency of biological treatment, even considering the above limitations.

\section{Image analysis contribution to protozoan identification}

About 230 species of protozoa have been identified in the wastewater treatment plants: 33 flagellates, 25 rhizopodi, 6 actinopodi and 160 ciliates [19]. Fortunately, only a small number of them occur frequently and most are cosmopolitan species present throughout the world $[17,18,36,43]$. Two of the major drawbacks to using protozoa for wastewater treatment diagnosis are the need for skilled workers in protozoology and the time it takes to be carried out. Image analysis is currently a well-established complement of optical and electronic microscopy. It allows for routine classification and quantification of microorganisms in an automated and nonsubjective manner. The most common applications are as diverse as the enumeration of bacteria in solid foods, in situ microscopy for online fermentation monitoring and texture analysis of colonies [39]. With the exponential increase in the processing capabilities of computers as well as their price reduction, image analysis has become a routine in cellular technology studies. A program was created to semiautomatically analyse protozoan digitised images. A principal component analysis technique was explored for species identification [2]. In that work, the morphology of the main protozoan species present in waste- 
water treatment plants was analysed in terms of several mathematical morphology parameters in order to identify different protozoa groups. After data collection and mathematical treatment a three-dimensional representation was generated and several protozoa species could be completely separated from the others. To our knowledge, this work is the first contribution towards completely automatic analysis of the protozoan community present in activated sludge and may be of considerable interest, especially in the case of well-established sludge, rendering the timeconsuming monitoring of a well-documented community a much easier task. However, an expert team will always be needed to validate the quality and feasibility of the results, as well as to overcome the problems that computation cannot solve, such as differentiation of similar species.

\section{Toxicological studies using ciliated protozoa as test organisms}

Over recent years, much research has been carried out on the toxicity of various relevant toxic compounds in a series of biotests using several test organisms. The appeal of these tests lies in their simplicity and high degree of reproducibility. However, test organisms for assessing environmental risk and impact must possess a number of desirable features: they must be eukaryotic, their biology and general responses must be well known, laboratory handling must be relatively easy and a short generation time is desirable whenever studies of long-term effects are necessary [29]. Ciliated protozoa fulfill all these requirements. Furthermore, as they have wide distribution and ecological significance, performing key functions in energy flow and elementary cycling in aquatic food webs, they can be ideal early-warning indicators of aquatic ecosystem deterioration [38]. Recently, the use of ciliates in toxicological tests has been investigated and their potential in standard bioassays has been demonstrated in aquatic environments [15, 30] and elsewhere [4].

The ciliated $T$. pyriformis was for more than four decades the organism of choice in analyses, evaluation of protein quality and determination of effects of several toxic substances. Moreover, it was the first protozoon to be cultivated axenically, i.e., in a standard medium, free from bacteria or other organisms, making it a suitable model cell system, since the addition of a compound is, in principle, the only change in culture conditions.

\section{Toxicological assays with $T$. pyriformis}

The sensitivity of protozoa to environmental changes suggested a study on the physiological responses arising from exposure to toxic compounds. In the literature, reports exist which are devoted to separate studies of growth, mortality, grazing or biochemical changes of protozoa, namely $T$. pyriformis, in the presence of toxicants $[6,7,24,28,31,33,40]$. An integrated approach searching for interactions between these parameters was missing. In our conceptual framework presented in figure 1, these parameters were considered in order to collect data at the species level. Consequently, growth, viability/mortality, grazing ability, ATP (adenosine-5' -triphosphate) content, ACP (acid phosphatase) activity and MTT (3-[4,5dimethyl-thiazol-2-yl]-2,5-diphenyl-tetrazolium bromide) reduction were evaluated simultaneously in a series of miniaturised assays using axenic cultures of T. pyriformis $[6,7,26]$. The final goal of this approach was to collect data in order to compare the physiological response patterns of the protozoa to different toxic compounds. The toxicants used were copper (as dihydrated copper choride), zinc (as zinc chloride), Triton X-100 and cycloheximide.

Results are with reference to soluble concentrations, in the case of heavy metals, since most metal ions suffer from binding effects due to the organic matter of the culture medium. Soluble concentrations of heavy metals were obtained after dialysis of the PPY medium through a cellulose membrane of 3500 D (molecular weight cut-off). For each concentration, two replicates of $10 \mathrm{~mL}$ were subjected to dialysis for $24 \mathrm{~h}$ in $5 \mathrm{~L}$ of deionised tap water with $0.02 \mathrm{~g} \mathrm{~L}^{-1}$ of sodium azide, at $20 \pm 1^{\circ} \mathrm{C}$. This water was renewed three times, after which both copper and zinc remaining in the medium were determined by photometric Merck spectroquant methods, after acid digestion with nitric acid (65\%). This was considered to be the amount of metal bound to the dissolved organic matter, allowing determination of the true bioavailable fraction of each metal. Less than $1 \%$ of total protein was lost during dialysis. Protein was determined by the Sigma microprotein determination method, based on the Biuret and Lowry procedures.

Prior to the toxicity assays, a control assay was performed to investigate the influence of the chloride ion 


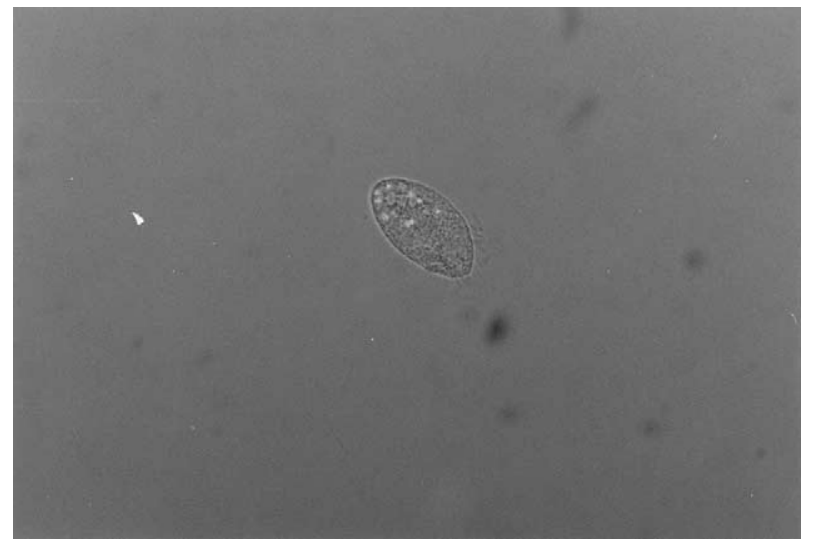

Figure 3. T. pyriformis with ingested fluorescent beads in the grazing assay (amp. 100×).

present in copper and zinc assays using sodium chloride. No effect was detected in terms of growth, mortality or grazing ability at the chloride concentrations of the metal assays.

\subsection{Physiological toxicological assays}

Growth and mortality assays were carried out simultaneously. Grazing assays used fluorescent labelled latex beads of $0.5 \mu \mathrm{m}$ diameter (figure 3), assuming that ciliates do not discriminate between different particles on the basis of properties other than size and shape [37].

Table I shows results of all toxicological assays after $48 \mathrm{~h}$, except for the grazing assay which was accomplished in 20 min. Data indicate that zinc was more toxic than copper for T. pyriformis in the tested conditions, in contrast to other studies in which copper was systematically considered more toxic than zinc to protozoa [20,21], to bacterial communities of activated-sludge or even to algae. Madoni et al. [20] define the sequence $\mathrm{Cu}>\mathrm{Hg}>\mathrm{Cd}>\mathrm{Pb}>\mathrm{Cr}>\mathrm{Zn}$ to order the toxicity of heavy metals for a series of species of protozoa taken from a community of activated sludge tested in vitro and not fed during the tests. They define a slightly different sequence for the toxicity of metals to a community of protozoa studied as a whole under field conditions: $\mathrm{Cd}$, $\mathrm{Cu}>\mathrm{Pb}>\mathrm{Zn}>\mathrm{Cr}[21]$. In the present study, $T$. pyriformis was cultured as the sole species in a nutrientrich medium and the tests were performed under the same conditions, without additional stress from starvation, competition for food or change of environmental conditions. This may partially explain the strong differences in the concentrations that proved to be toxic to the organisms involved. Protection of organic growth medium against the toxic effects of heavy metals on Tetrahymena is ascribed to the binding or chelating of heavy metals to organic compounds, thus leaving little in the ionic form [29-31, 38]. Would this explain the initial difference in the concentration of copper tolerated by cells in the presence and absence of organic matter? Results of dosing after dialysis seem to indicate that this may not be the only cause and that toxicity will also depend on the physiological state of the organisms. Nilsson [28] reports that cells forming granules are resistant to higher concentrations of copper and states that these granules can be regarded as structures involved in detoxification and metal ion regulation. In the present experiment, granules were not initially looked for, and confirmation of this detoxification mechanism cannot be given. Madoni et al. [21] found $\mathrm{LC}_{50}$ values of $0.31-2.05 \mathrm{mg} \mathrm{L}^{-1}$ of copper and $0.57-50.0 \mathrm{mg} \mathrm{L}^{-1}$ of zinc for protozoa in an activated sludge community. These values were even lower for cell suspension protozoa, as they are unfed. In the present study $\mathrm{LC}_{50}$ was not determined but mortality of around $50 \%$ in $24 \mathrm{~h}$ was determined for much higher values, e.g. above $200 \mathrm{mg} \mathrm{L}^{-1}$ copper or $45 \mathrm{mg} \mathrm{L}^{-1}$ zinc. Yamaguchi et al. [42] observe complete inhibition of growth of $T$. pyriformis in axenic cultures at $1 \mathrm{mM}$ copper (approximately $63.5 \mathrm{mg} \mathrm{L}^{-1}$ ). In the present study, this value occurred at $275 \mathrm{mg} \mathrm{L}^{-1}$, though at a concentration of $145 \mathrm{mg} \mathrm{L}^{-1}$, growth was reduced. In contrast, Piccinni et al. [31] observed no effect on growth following addition of copper to axenic cultures of T. pyriformis at a concentration of $10 \mathrm{mg} \mathrm{L}^{-1}$. Nilsson [28] states that the addition of $100 \mathrm{mg} \mathrm{L}^{-1}$ copper (nominal concentration) to the normal $2 \%$ proteose peptone medium is tolerated by Tetrahymena and stimulates phagocytosis; cell proliferation is observed to resume after a lag period, but at a decreased rate. These results are in accordance with those of the present work.

Studies on the influence of different toxicants on the grazing capacity of ciliates have not been recently carried out, but some authors state that heavy metals at low concentrations may stimulate grazing [28, 40], which, in our study, is supported for copper but not for zinc (table I). Additional assays were made to test the possible influence of lower concentrations of zinc on grazing, but at 25.0 and $12.5 \mathrm{mg} \mathrm{L}^{-1}$, no stimulation of grazing was observed. 
Table I. Results (average values of two independent assays of three replicas each) of toxicological assays using T. pyriformis.

\begin{tabular}{|c|c|c|c|c|c|c|c|}
\hline Toxicant $(\mathrm{mg} / \mathrm{L})^{\mathrm{a}}$ & & Mortality $^{b}$ & Growth $^{\mathrm{c}}$ & Grazing $^{c}$ & $\mathrm{ATP}^{\mathrm{c}}$ & $\mathrm{ACP}^{\mathrm{c}}$ & $\mathrm{MTT}^{\mathrm{c}}$ \\
\hline \multirow[t]{5}{*}{ Copper } & 30.0 & 0.0 & 47.0 & 135.0 & 50.3 & 117.3 & 90.8 \\
\hline & 65.0 & 0.0 & 27.2 & 114.5 & 24.9 & 153.3 & 57.6 \\
\hline & 145.0 & 0.0 & 9.7 & 8.8 & 20.2 & 133.3 & 30.6 \\
\hline & 200.0 & 1.7 & 4.6 & 3.0 & 14.9 & 98.8 & 12.6 \\
\hline & 275.0 & 19.7 & 2.4 & 3.3 & 8.2 & 54.3 & 7.0 \\
\hline \multirow[t]{4}{*}{ Zinc } & 15.0 & 0.0 & 41.8 & 8.0 & 54.5 & 98.4 & 61.6 \\
\hline & 45.0 & 5.3 & 11.6 & 3.2 & 17.0 & 77.8 & 62.4 \\
\hline & 120.0 & 63.4 & 1.5 & 1.4 & 10.8 & 65.1 & 20.2 \\
\hline & 200.0 & 100.0 & 1.5 & 0.0 & 0.7 & 39.7 & 5.2 \\
\hline \multirow[t]{4}{*}{ Triton X-100 } & 12.5 & 0.0 & 88.0 & 57.0 & 78.3 & 92.3 & 73.3 \\
\hline & 25.0 & 0.0 & 71.5 & 37.8 & 67.4 & 93.8 & 59.9 \\
\hline & 37.5 & 0.0 & 1.1 & 2.5 & 76.6 & 83.1 & 51.8 \\
\hline & 50.0 & 100.0 & 0.6 & 1.4 & 43.2 & 66.2 & 14.4 \\
\hline \multirow[t]{5}{*}{ Cycloheximide } & 0.0002 & 0.0 & 30.4 & 91.4 & 283.6 & 232.5 & 106.6 \\
\hline & 0.001 & 0.0 & 0.5 & 42.3 & 241.0 & 317.5 & 118.2 \\
\hline & 0.01 & 0.1 & 0.3 & 24.7 & 93.8 & 292.5 & 101.2 \\
\hline & 0.1 & 0.1 & 0.2 & 14.1 & 55.2 & 247.5 & 68.6 \\
\hline & 1.0 & 0.1 & 0.2 & 11.0 & 2.4 & 42.5 & 16.7 \\
\hline
\end{tabular}

${ }^{\mathrm{a}}$ Concentrations are soluble concentrations of the toxicant.

${ }^{\mathrm{b}}$ Expressed in terms of percentage of total individuals.

${ }^{\mathrm{c}}$ Expressed in terms of percentage related to the control observations.

As a surfactant, Triton X-100 disrupts all cell membranes above a certain concentration. There are no other studies available on the toxicity of surfactants on $T$. pyriformis or on other ciliates, with which the results of exposure to Triton X-100 can be compared.

Cycloheximide, an antibiotic that inhibits protein synthesis, did not cause mortality but inhibited the growth and the grazing capacity of $T$. pyriformis.

\subsection{Biochemical toxicological assays}

Assays of ATP content have been widely used to characterise biomass viability [13] and to detect potential spoilage microorganisms in the beer and food industry $[8,12]$, assuming that it is possible to use the concentration of ATP to measure the viable cells of a certain species. In the work mentioned above, ATP content was determined to give information about the general energetic state of the culture when submitted to the toxicants.
Previous works have been devoted to studying the ACP activity of other hydrolases to detect digestive activity in protozoa $[22,32,34,35,41]$, since there is an intimate relationship between lysosomal function and intracellular digestion in Tetrahymena and other ciliates. In the referred work, ACP activity was used as an indicator of the metabolic state of the cultures, namely of the intracellular digestive function.

Colorimetric assays based on tetrazolium dye reduction, like MTT, have been extensively used in the in vitro evaluation of cellular proliferation and cytotoxicity as well as screening for additives, mycotoxins or anticancer drugs. The MTT assay is a quantitative method that consists of metabolic reduction of the tetrazolium dye, a group of water-soluble quaternary ammonium compounds, by dehydrogenases of viable immobilised or suspended cells. Production of intensely coloured formazan water-insoluble crystals is the result of the tetrazolium reduction assay. Formazan crystals can be either observed microscopically in the cell cytoplasm or extracted and dissolved 
with organic solvents, such as DMSO, enabling spectrophotometric quantification [25].

Suspended cells in culture do not adhere to the bottom of the well, leading to a loss of cells during the medium removal step, and further reading is impaired. To overcome this limitation, a modification of the tetrazolium-based MTT assay was implemented, enabling the innovative application of this method to free-swimming protozoa [7].

The results of assays on ATP content, ACP activity and MTT reduction are also shown in table I. In most cases, increasing concentrations of toxicants caused increasing inhibition of the physiological responses of $T$. pyriformis, but in some cases toxicants caused stimulation of ATP content or ACP activity.

Zinc and Triton X-100 affected T. pyriformis negatively, and significant values of Kendall's coefficient of correlation between the ACP activity and ATP content indicate that zinc and Triton X-100 similarly affect these two parameters in the range of concentrations assayed. A positive correlation between these two parameters was expected: energy is needed for phagocytosis of food particles, anabolism, synthesis of enzymes and the activity of these enzymes. MTT is also inhibited by all assayed concentrations of Triton $\mathrm{X}-100$ and zinc.

Copper, in contrast, decreased MTT reduction and ATP content at all assayed concentrations, but some concentrations stimulated ACP activity. All but one were also the concentrations that stimulated grazing activity in the previous study [26]. This coincidence is quite satisfying since ACP activity reflects lysosomal function and thus intracellular digestion in ciliated protozoa: they ingest food molecules endocytically from the environment in membrane-limited vacuoles (food-vacuoles or phagosomes); after ingestion, the latter are fused with one or more lysosomes and the hydrolytic enzymes of the latter then digest the content of the newly formed phagolysosome. Small molecular weight products of digestion can then pass through the membrane of the phagolysosome and be utilised by the cell. Surprisingly, there was a decrease in ATP content at these three concentrations, meaning that there was a lower energy level available for increased grazing and ACP activities. The study of longer exposure times would be of great interest for determining the long-term consequences of ATP content decrease on cellular functions, such as grazing and ACP activity.
Finally, in the cycloheximide assay, ATP and MTT were stimulated by the lowest concentrations and were virtually unaffected by others, but there is clearly a more complex set of influences in the case of ACP activity, perhaps including the disposable energy amount and some related energy-dependent functions such as enzyme synthesis, enzyme activity and even grazing itself. The fact that cycloheximide is a toxicant toward eukaryotic organisms by inhibiting protein synthesis at the $80 \mathrm{~S}$ but not at the $70 \mathrm{~S}$ ribosomes, makes interpretation of data difficult, especially at lower concentrations where toxic effects are not as drastic.

\subsection{New approaches to the determination of viability and death in toxicological assays}

Population growth impairment is the most frequently used sublethal toxic endpoint [23]. A growth/ mortality bioassay using microscopic observation of morphological changes at low magnification is a simple reproducible technique that does not require technical expertise or operational expenses [26]. Nevertheless, some limitations detected in such an assay can make it unsuitable with several toxicants. Recognising dead cells was sometimes ambiguous, since nonmotile cells as well as altered shape cells were counted as dead cells. It was found that light microscopy observations underestimated the true number of viable cells, i.e. false-negative counting, since several abnormal cells were not in fact dead. Indeed, they recovered their normal shape immediately after toxicant removal and began growing in the recovery assay. As verified, Triton X-100 is a detergent that has reversible effects at concentrations under $100 \mathrm{mg} / \mathrm{L}$, if cells are removed immediately after contact with the toxicant. Agents such ethidium bromide [24] and dimethyl sulphoxide [27] were reported to alter the morphology of Tetrahymena sp. with reversible effects, with the cells able to grow after toxicant removal. On the other hand, when using another toxicant such as copper, light microscopy observations provided overestimated or false-positive counting as, when transferred to dilute medium, cells treated with some concentrations of copper and considered alive did not grow in the recovery assays, showing they were nonviable.

A novel cellular cytotoxicity assay using two fluorescent dyes was developed as an alternative method to standard direct counting of viable protozoa under light microscopy. The compound calcein/AM is a 


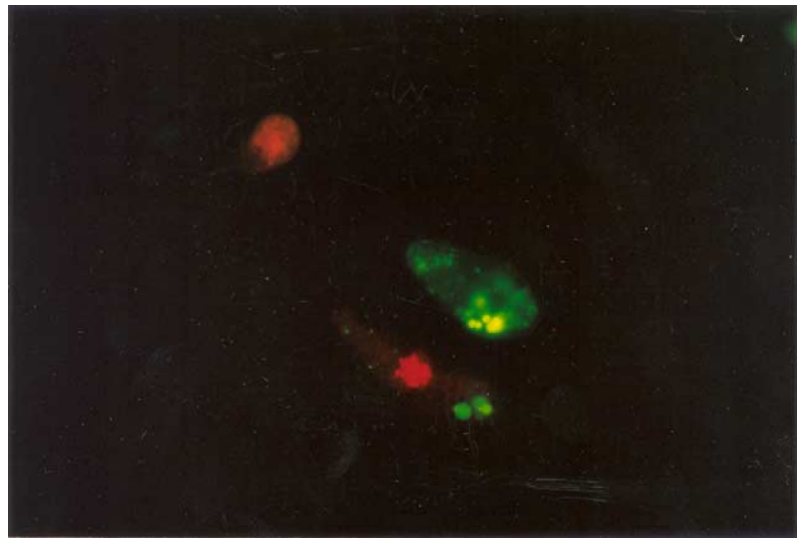

Figure 4. Viable and nonviable T. pyriformis, using calcein/AM and EthD-1. The two nonviable cells show red stained nuclei.

nonfluorescent substance that diffuses passively into cells and is converted by intracellular esterases to green fluorescent calcein in viable cells. EthD-1, that binds to DNA-stained red dead cells, was also added. These dyes were used to assess the viability of the ciliated protozoa $T$. pyriformis after exposure to Triton X-100 and copper at several concentrations (figure 4). In a shorter time exposure, less than $1 \mathrm{~h}$ of contact with the toxicants at sublethal concentrations, the fluorescent method proved to be more sensitive and provided more accurate results than direct counting under light microscopy. With increasing exposure time, the results obtained for both methods were similar. However, fluorescent methods provide new opportunities for using advanced techniques, such as flow cytometry or image analysis, to assess cytotoxicity in protozoa.

\section{Conclusions}

Protozoa have proven to be excellent tools for assessessing the occurrence of pollution during wastewater biological treatment, along with its role in the control of pollution itself, through the grazing of dispersed bacteria and maintenance of a healthy trophic web in those artificial ecosystems. The protozoan community in the aeration tank of activated sludge plants remains an innovative and useful instrument to monitor biological wastewater treatment. More studies on this subject, aimed at collecting data and comparing the effects of toxicants on this community, will be of great interest and should make the protozoa a better tool in the monitoring of these processes.
The use of protozoa as actual test organisms was validated as well. Conventional toxicological assays are often slow and labour-intensive, and become impractical when many compounds and/or concentrations are being tested rapidly. This has led to a greater interest in colorimetric and fluorimetric assays that can be miniaturised in 96-well microtitre plates and assessed using an ELISA spectrophotometric microtitre plate reader [23]. In this respect, the ATP content, ACP activity and MTT reduction assays and the use of protozoa seem to be excellent options: they allow for simultaneous tests of different toxicants at various concentrations and even in this case are rapid and easy to carry out. ATP content, ACP activity and MTT reduction assays may be good alternatives to conventional toxicological tests using suspension cultures - since they are based on growth or mortality. The grazing activity test is by far the least labour-intensive and time-consuming, even when studies of mortality and/or growth of protozoa are involved. They do not require technical expertise or operational expenses that are needed in bioassays carried out by regulatory agencies at higher trophic levels such as in fish.

The results obtained should encourage further research on possible response patterns to other toxic compounds. Furthermore, this study may be enlarged to other significant protozoa present in activated sludge.

\section{Acknowledgements}

The authors acknowledge the financial support provided by the Instituto de Biotecnologia e Química Fina (IBQF) and the Fundação para a Ciência e Tecnologia (Projecto PRAXIS XXI-2/2.1/BIO/1118/95). Ana Nicolau and Nicolina Dias were supported by grants PRAXIS XXI/BD/5080/95 and PRAXIS XXI/ $\mathrm{BD} / 20328 / 99$, respectively.

\section{References}

[1] Abraham J.V., Butler R.D., Sigee D.C., Ciliate populations and metals in an activated-sludge plant, Water Res. 31 (1997) 1103-1111.

[2] Amaral A.L., Baptiste C., Pons M.N., Nicolau A., Lima N., Ferreira E.C., Mota M., Vivier H., Semi-automated recognition of protozoa by image analysis, Biotechnol. Tech. 13 (1999) 111-118. 
[3] Battistoni P., Fava G., Ruello M.L., Heavy metal shock load in activated sludge uptake and toxic effects, Wat. Res. 27 (1993) 821-827.

[4] Benitez L., Martin-Gonzalez A., Gilardi P., Soto T., Rodriguez de Lecea J., Gutiérrez J.C., The ciliated protozoa Tetrahymena termophila as a biosensor to detect micotoxins, Lett. Appl. Microb. 19 (1994) 489-491.

[5] Curds C.R., Protozoa, in: Curds C.R., Hawkes H.A. (Eds.), Ecological Aspects of Used Water Treatment, Academic Press, London, 1975, pp. 203-268.

[6] Dias N., Nicolau A., Lima N., Carvalho G.S., Mota M., The use of immunocytochemical methods for toxicity assessment in Tetrahymena pyriformis, Cuad. Invest. Biol. (Bilbao) 20 (1998) 75-78.

[7] Dias N., Nicolau A., Carvalho G.S., Mota M., Lima N., Miniaturization and application of the MTT assay to evaluate metabolic activity of protozoa in the presence of toxicants, J. Basic Microbiol. 39 (1999) 103-108.

[8] Dowhanick T.M., Sobczak J., ATP bioluminescent procedure for viability testing of potential beer spoilage microorganisms, J. Am. Soc. Brew. Chem. 52 (1994) 19-23.

[9] Esteban G., Tellez C., Bautista L.M., Effects of habitat quality on ciliated protozoa communities in sewage treatment plants, Envir. Technol. 12 (1990) 381-386.

[10] Fernandez-Leborans G., Novillo A., The effects of cadmium on the successional stages of a freshwater protozoa community, Ecotoxicol. Environ. Safety 31 (1995) 29-36.

[11] Fernandez-Leborans G., Novillo A., Protozoan communities and contamination of several fluvial systems, Wat. Environ. Res. 68 (1996) 311-319.

[12] Gamborg G., Hansen E.H., Flow-injection bioluminescent determination of ATP on the use of the luciferin-luciferase system, Anal. Chim. Acta 285 (1994) 321-328.

[13] Gikas P., Livingston A.G., Use of ATP to characterize biomass viability in suspended and immobilized bioreactors, Biotechnol. Bioeng. 42 (1993) 1337-1351.

[14] Gracia M.P., Salvadó H., Rius M., Amigó J.M., Effects of copper on ciliate communities from activated sludge plants, Acta Protozool. 33 (1994) 219-226.

[15] Le Dû A., Modulation of copper toxicity by the chemical parameters of river water, Fresenius Envir. Bull. 2 (1993) 629-634.

[16] Lynn D.H., Gilron G.L., A brief review of approaches using ciliated protists to assess aquatic ecosystem health, J. Aquatic Ecosys. Health 1 (1992) 263-270.

[17] Macek M., Experimental approach to the role of different ecological types of protozoa in the activated sludge system, Int. Revue Ges. Hydrobiol. 74 (1989) 643-656.

[18] Madoni P., Comparative analysis of the activated sludge microfauna in several sewage treatment works, Water Res. 9 (1993) 1485-1491.

[19] Madoni P., A sludge biotic index (SBI) for the evaluation of the biological performance of activated sludge plant based on the microfauna analysis, Water Res. 28 (1994) 67-75.

[20] Madoni P., Davoli D., Gorbi G., Acute toxicity of lead, chromium and other heavy metals to ciliates from activated sludge plants, Bull. Environ. Contam. Toxicol. 53 (1994) 420-425.
[21] Madoni P., Davoli D., Gorbi G., Vescovi L., Toxic effects of heavy metals on the activated sludge protozoan community, Water Res. 30 (1996) 135-141.

[22] Martin A., Clydes M., Acid phosphatase endpoint for in vitro toxicity tests, In Vitro Cell. Dev. Biol. 27A (1991) 183-184.

[23] Martin A., Clynes C., Comparison of 5 microplate assays for in vitro cytotoxicity testing and cell proliferation assays, Cytotechnology 11 (1993) 49-58.

[24] Meyer R.R., Boyd C.R., Rein D.C., Keller S.J., Effect of ethidium bromide on growth and morphology of Tetrahymena pyriformis, Exptl. Cell Res. 70 (1971) 233-237.

[25] Mossman T., Rapid colorimetric assay for cellular growth and survival: application to proliferation and cytotoxicity assays, J. Immunol. Methods 65 (1983) 55-63.

[26] Nicolau A., Mota M., Lima N., Physiological responses of Tetrahymena pyriformis to copper zinc cycloheximide and Triton X-100, FEMS Microb. Ecol. 30 (1999) 209-216.

[27] Nilsson J.R., Effects of DMSO on vacuoles formation contractile vacuole function and nuclear division in Tetrahymena pyriformis GL, Cell Sci. 16 (1974) 39-47.

[28] Nilsson J.R., Effects of copper on phagocytosis in Tetrahymena, Protoplasma 109 (1981) 359-370.

[29] Nilsson J.R., Tetrahymena in Citotoxicology: with special reference to effects of heavy metals and selected drugs, Eur. J. Protistol. 25 (1989) 2-25.

[30] Pauli W., Berger S., Jaskulka L., Schmitz S., A case for the inclusion of a protozoan test in aquatic toxicity assessment using Tetrahymena, Sci. Total Environ. Supplem. (1993) 779-786.

[31] Piccinni E., Irato P., Coppelloti O., Guidolin L., Biochemical and ultrastructural data on Tetrahymena pyriformis treated with copper and cadmium, J. Cell Sci. 88 (1987) 283-293.

[32] Ricketts T.R., Rappit A.F., The adaptative acid phosphatase of Tetrahymena pyriformis GL-9. Effect of endocytosis of various nutrients, Protoplasma 85 (1975) 119-125.

[33] Roberts Jr. Ch.T., Orias E., A cycloheximide-resistent mutant of Tetrahymena pyriformis, Exptl. Cell Res. 81 (1973) 312-316.

[34] Rothstein R.L., Blum J.J., Lysosomal physiology in Tetrahymena. II Effect of culture age and temperature on the extracellular release of 3 acid hydrolases, J. Protozool. 21 (1974) 163-168.

[35] Rothstein R.L., Blum J.J., Lysosomal physiology in Tetrahymena. III Pharmacological studies on acid hydrolase, J. Cell Biol. 62 (1974) 844-859.

[36] Salvadó H., Garcia M.P., Amigó J.M., Capability of ciliated protozoa as indicators of effluent quality in activated sludge plants, Water Res. 29 (1995) 1041-1050.

[37] Sherr B.F., Sherr E.B., Fallon R.D., Use of monodispersed, fluorescently labelled bacteria to estimate in situ protozoan bacterivory, Appl. Environ. Microbiol. 53 (1987) 958-965.

[38] Twagilimana L., Bohatier J., Groliere C.A., Bonnemoy F., Sargos D., A new low-cost microbiotest with the protozoan Spirostomum teres: culture conditions and assessment of sensitivity of the ciliate to 14 pure chemicals, Ecotoxicol. Environment. Saf. 41 (1998) 231-244.

[39] Vecht-Lifshitz S.E., Ison A.P.J., Biotechnological application of image analysis: present and future perspectives, J. Biotechnol. 23 (1992) 1-18. 
[40] Wakatsuki T., Takasi Y., Imahara H., Respiratory inhibition by copper in Tetrahymena pyriformis GL, J. Ferment. Technol. 64 (1986) 119-127.

[41] Williams J.T., Juo P.S., Release and activation of a particulate bound acid phosphatase from Tetrahymena pyriformis, Biochim. Biophys. Acta 422 (1976) 120-126.
[42] Yamaguchi N., Wada O., Ono T., Takasi K., Toyokawa K., Detection of heavy metal toxicity by $T$. pyriformis culture method, Ind. Health 11 (1973) 27-31.

[43] Yun Fen S., Buikema Jr.A.L., Yongue Jr.W.H., Pratt J.R., Cairns Jr. J., Use of protozoa communities to predict environmental effects of pollutants, J. Protozool. 33 (1986) 146-151. 